\title{
Austenitic Stainless-Steel Reinforcement for Seawater Sea Sand Concrete: Investigation of Stress Corrosion Cracking
}

\author{
Xiang Yu ${ }^{1}$, Saad Al-Saadi ${ }^{2}$, Isha Kohli ${ }^{2}$, Xiao-Ling Zhao ${ }^{3}$ and R. K. Singh Raman ${ }^{1,2, * \mathbb{D}}$ \\ 1 Department of Chemical Engineering, Monash University, Clayton, VIC 3800, Australia; \\ xiang.yu@monash.edu \\ 2 Department of Mechanical and Aerospace Engineering, Monash University, Clayton, VIC 3800, Australia; \\ saad.al-saadi@monash.edu (S.A.-S.); Isha.Kohli1@monash.edu (I.K.) \\ 3 School of Civil and Environmental Engineering, University of New South Wales, \\ Sydney, NSW 2052, Australia; xiaolin.zhao@unsw.edu.au \\ * Correspondence: raman.singh@monash.edu
}

Citation: Yu, X.; Al-Saadi, S.; Kohli, I.; Zhao, X.-L.; Singh Raman, R.K.

Austenitic Stainless-Steel

Reinforcement for Seawater Sea Sand Concrete: Investigation of Stress Corrosion Cracking. Metals 2021, 11, 500. https://doi.org/10.3390/ met11030500

Academic Editor: Anna Hojná

Received: 20 February 2021

Accepted: 13 March 2021

Published: 17 March 2021

Publisher's Note: MDPI stays neutra with regard to jurisdictional claims in published maps and institutional affiliations.

Copyright: (C) 2021 by the authors Licensee MDPI, Basel, Switzerland This article is an open access article distributed under the terms and conditions of the Creative Commons Attribution (CC BY) license (https:// creativecommons.org/licenses/by/ $4.0 /)$
Abstract: Seawater and sea sand concrete (SWSSC) is a highly attractive alternative to normal concrete (NC) that requires huge amounts of fresh water and river sand. However, reinforcements of stainless steel (instead of mild steel that is used in NC) may be required for SWSSC. This article reports investigation of stress corrosion cracking (SCC) of AISI 316 stainless steel (SS) in simulated SWSSC and NC environments, with and without addition of silica to SWSSC and NC, employing slow strain rate testing (SSRT) at 25 and $60^{\circ} \mathrm{C}$. For the purpose of comparison, SCC of SS was also investigated in simulated seawater (SW) solution. SS showed no SCC at $25^{\circ} \mathrm{C}$ in any of the test solutions. Indications of SCC were seen in SW at $60^{\circ} \mathrm{C}$, but no features of SCC in SWSSC and NC at $60^{\circ} \mathrm{C}$, as suggested by scanning electron microscopy (SEM) fractographs. While the absence of SCC in SWSSC and NC is attributed to the highly passivating alkaline condition, its absence in SWSSC also indicates the role of alkalinity to predominate the deleterious role of chloride content of SWSSC. However, the addition of silicate to SWSSC or NC triggers transgranular SCC to SS at $60{ }^{\circ} \mathrm{C}$, as evidenced by the fractography.

Keywords: seawater sea sand concrete; normal concrete; stress corrosion cracking; AISI 316 stainless steel; slow strain rate testing (SSRT)

\section{Introduction}

Increasing population and industrial development cause a rapid increase in the demand of concrete. Concrete production requires massive amounts of fresh water that contributes significantly to water scarcity [1-3]. Concretes also use huge amounts of river sand that negatively impacts the river ecosystem, navigation and flood control [4]. In order to circumvent these problems, the use of seawater and sea sand concrete (SWSSC) is an attractive alternative. SWSSC is a recent type of concrete that can be improved further by use of alkali-activated slag as binding material. The mechanical properties of SWSSC are reported to be similar to those of the conventional Portland cement concrete [5-7]. The Japan Concrete Institute reported that the strength of the slag-containing concrete produced with seawater tends be higher as compared to the concrete produced using tap water [8]. Furthermore, the alkali-silica reaction has a detrimental effect on integrity of ordinary Portland cement concrete $[9,10]$, whereas the geo-polymer concrete or the high-performance concrete that utilizes industrial waste materials such as fly ash or slag, instead of cement, is designed to reduce effect of the alkali-silica reaction.

Generally, mild steel rebars are employed as reinforcements to the concrete for high tensile strength and ductility; however, austenitic stainless steels have also been used because of their greater corrosion resistance. Steel bars develop a protective passive layer in the highly alkaline environment of concrete $(\mathrm{pH}>10)$ [11]. However, this layer can be 
disrupted by chloride and other deleterious ions that diffuse from the marine or industrial environment through the concrete matrix on to the steel reinforcement surface, resulting in rapid corrosion of the bars. It is common to find the voluminous products of such rapid corrosion causing cracks and spallation of concrete (called "concrete cancer"), thereby seriously jeopardizing the durability of concrete structures. Therefore, the premature failure of reinforced concrete structure due to the corrosion of steel reinforcement is regarded as a critical durability problem that is a concern even for the normal reinforced concrete structures [12,13]. Such deterioration of steel reinforced concrete results in high repair and maintenance costs [14]. With the very-high chloride content of seawater, it is obvious that the corrosion rate of the traditional reinforcement of mild steel will be unacceptably high in SWSSC. Consequently, reinforcement of steels with much superior resistance to chlorideassisted corrosion, such as stainless steels (SS) may be required as replacement for mild steel. Stainless steel (SS) possesses superior corrosion resistance due to the presence of a very thin, robust, self-healing, passivating and protective surface layer of chromium oxide.

Cramer et al. [15] reported that the replacement of mild steel reinforcements with SS decreases maintenance costs by $>50 \%$ with the projected service lives of normal concrete exceeding far greater than 100 years. Austenitic SS, AISI316, is among the most commonly used SS alloys where good corrosion resistance is required. SS 316 contains $16-18 \%$ chromium, $8-10 \%$ nickel and $2 \%$ molybdenum. Molybdenum is added for improving pitting corrosion resistance in chloride environment (such as seawater and deicing salts) [15]. However, too high chloride concentrations can disrupt the chromium oxide protective layer of SS, compromising their corrosion resistance and resulting in localized corrosion such as pitting [16,17].

Even though SS possesses significantly superior corrosion resistance compared with mild steel, they are susceptible to stress corrosion cracking (SCC), i.e., cracking of metals and alloys due to the synergistic action of corrosion and tensile stress [16]. SCC can result in a sudden, catastrophic and brittle form of fracture that eventuates because a crack initiates and sub-critically propagates, and a premature failure of components can consequently occur. Because SCC may occur at stresses below yield strength, it is among the most dangerous forms of corrosion-assisted fracture. Sometimes, residual stresses from fabrication or environments with small concentrations of harmful components may be sufficient to cause unexpected SCC $[18,19]$. Since pitting is among the common initiators of SCC [18], the ability of chloride in enhancing pitting susceptibility of SS becomes an obvious concern in using SS as reinforcement for SWSSC. Another application of the combination of SWSSC and SS is in the hybrid construction with SWSSC filled SS tubes [20].

There is already a range of studies focusing on the role of key variables in determining the susceptibility of SS to SCC. For example, Raman et al. [21] found pitting to be one of the common SCC-initiators, where the localized crack-tip dissolution facilitated crack propagation which is consistent with other published literature (e.g., [22,23]). A suitable synergy of mechanical loading and environmental condition is required for SCC cracks to propagate [24]. For example, when the passive film is less stable in high chloride environment, straining of metal at too high a rate may not allow enough time for effective passivation. In terms of alkalinity of environment, Truman [25] concluded that generally solutions of high alkalinity were less likely to give rise to stress corrosion cracking. However, a suitable synergy of the role of $\mathrm{pH}$ in enabling passivation and the role of straining in disruption of the passive film is required for SCC cracks to propagate, as demonstrated by Raman [24].

As described earlier, there is great interest in seawater sea sand concrete (SWSSC), including in hybrid construction. In such applications, stainless steels (SS) are potential material for reinforcing bars or tubes. Thus, this paper investigates stress corrosion cracking of AISI 316 SS in different environment relevant to SWSSC, with and without silicate, by slow strain rate testing (SSRT). For comparison, the SSRT tests were carried out in presence of the simulated solutions of seawater and normal concrete (with and without silicate). Though SCC of austenitic SS in chloride and caustic solutions has been investigated considerably (e.g., [21-25]), influence of silicate, a constituent of concrete, on SCC has 
not been investigated earlier. To the best of authors' knowledge, this is the first report on deleterious role of silica in causing SCC to SS in concrete environment. This study investigates the role of a typical silicate addition to simulated concrete solutions in stress corrosion cracking of austenitic stainless-steel bars.

\section{Experimental Procedure}

The test samples were machined from the round bars of AISI 316 stainless steel (SS) which are procured from George Archer metals, Australia. The chemical composition of SS is ( $\mathrm{wt} \%$ ) is: C (0.027), $\mathrm{Mn}(1.800), \mathrm{Si}(0.360), \mathrm{S}(0.026), \mathrm{P}(0.038), \mathrm{Cr}$ (16.800), Ni (10.060), Cu (0.450), Mo (2.030), Co (0.190) and N (0.075). The tensile strength of the steel was $660 \mathrm{MPa}$. The uniaxial cylindrical tensile specimen had an outer diameter (OD) $8.0 \pm 0.2 \mathrm{~mm}$, with a gauge section of $3.0 \pm 0.2 \mathrm{~mm}$ OD and $20.0 \pm 0.2 \mathrm{~mm}$ length. Figure 1 presents a schematic diagram of the tensile specimens used in the present study. To determine the susceptibility to stress corrosion cracking in the simulated solutions of seawater, normal concrete, and seawater sea sand normal concrete, the slow strain rate testing (SSRT) was employed. To achieve different constant crosshead speeds (i.e., different strain rates), the SSRT rig is equipped with a controlled variable speed motor. The speed can be varied from $10 \%$ to $100 \%$ of the full motor speed that corresponds to various strain rates in the range of $10^{-7} \mathrm{~s}^{-1}$. SSRT rigs were constructed locally at Monash University, and the variable speed motors for these rigs were procured from Baldor Electric company (Fort Smith, AR, USA).

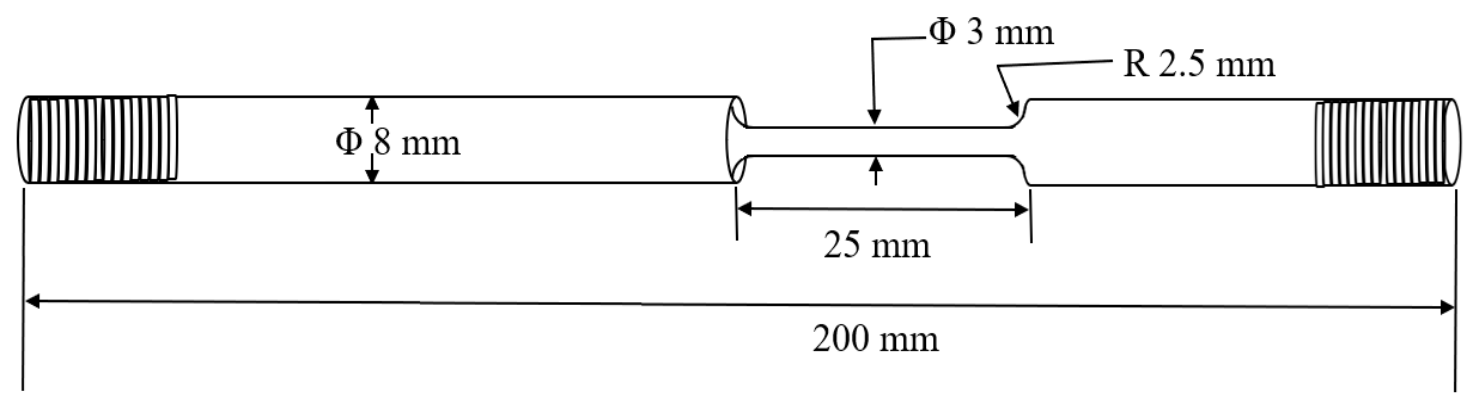

Figure 1. Schematic diagram of the tensile specimens used in the present study.

Prior to loading the SSRT sample on to the SSRT rig, the gauge section was ground in the longitudinal direction progressively to a 2500 grit finish, rinsed with acetone and air dried. A layer of Teflon tape was used to cover all of the specimen surface except the gauge section that is exposed to the test solution within the corrosion cell of the rig. A clean SS sample was mounted onto the SSRT rig and the test solution was circulated at a constant temperature. The temperature-controlled water bath was used to maintain the temperature of the test solution at the ambient temperature (i.e., $25^{\circ} \mathrm{C}$ ) or $60{ }^{\circ} \mathrm{C}$; the latter was selected to represent an extremely harsh condition. To examine the reproducibility, SSRT tests under each condition were duplicated.

Table 1 shows the chemical compositions and $\mathrm{pH}$ of the simulated solutions of normal concrete, with and without silicate addition (NC and NC_Sil) and seawater sea sand normal concrete, with and without silicate addition (SWSSNC and SWSSNC_Sil). As a reference $3.5 \% \mathrm{NaCl}$ solution was used to simulate the seawater (SW).

SSRT tests were continued until fracture of specimens. Fracture surface of the failed specimens were cleaned using an inhibited acidic solution (hydrochloric acid and hexamethylenetetramine) and examined using a scanning electron microscope (SEM, Hitachi, Tokyo, Japan), for characterization of the fracture mode and identification of stress corrosion cracking. 
Table 1. Chemical composition and $\mathrm{pH}$ of test solutions.

\begin{tabular}{ccccccc}
\hline \multirow{2}{*}{$\begin{array}{c}\text { Simulated Solution } \\
\text { Nomenclature }\end{array}$} & $\mathbf{N a O H}$ & $\mathbf{K O H}$ & $\mathbf{C a}(\mathbf{O H})_{2}$ & $\mathbf{N a C l}$ & $\mathbf{N a}_{2} \mathbf{S i O}_{3}$ & pH \\
\cline { 2 - 5 } & 2.4 & 19.6 & 2.0 & & & 13.4 \\
\hline NC $^{\text {a }}$ & 2.4 & 19.6 & 2.0 & 35 & & 13.4 \\
SWSSNC $^{\mathrm{b}}$ & 2.4 & 19.6 & 2.0 & & 3.0 & 13.4 \\
NC_Sil & 2.4 & 19.6 & 2.0 & 35 & 3.0 & 13.4 \\
SWSSNC_Sil & & & & 35 & & 7.5 \\
SW & & & & & \\
\hline
\end{tabular}

a Simulated normal concrete (NC) pore solution is prepared according to [26]. ${ }^{\mathrm{b}}$ seawater sea sand normal concrete (SWSSNC) simulated pore solution is prepared according to [27-30].

\section{Results and Discussion}

Figure 2a presents the stress vs. time curves of the SSRT specimens tested at the strain rate of $3.7 \times 10^{-7} \mathrm{~s}^{-1}$ at 25 and $60{ }^{\circ} \mathrm{C}$ in the simulated SW solution. Time to failure $\left(t_{f}=296 \mathrm{~h}\right)$ at $60^{\circ} \mathrm{C}$ was significantly shorter compared to that at $25^{\circ} \mathrm{C}(374 \mathrm{~h})$. The trend in the stress vs. elongation plots in Figure $2 b$ is consistent with that seen in Figure 2a, i.e., the specimens tested at $25{ }^{\circ} \mathrm{C}$ displayed both the elongation-to-failure $\left(\varepsilon_{f}=49.87 \%\right)$ and the ultimate tensile strength $(U T S=663 \mathrm{MPa})$ to be correspondingly higher than those of the specimens tested at $60{ }^{\circ} \mathrm{C}\left(\varepsilon_{f}=39.41 \%\right.$ and $\left.U T S=560 \mathrm{MPa}\right)$.
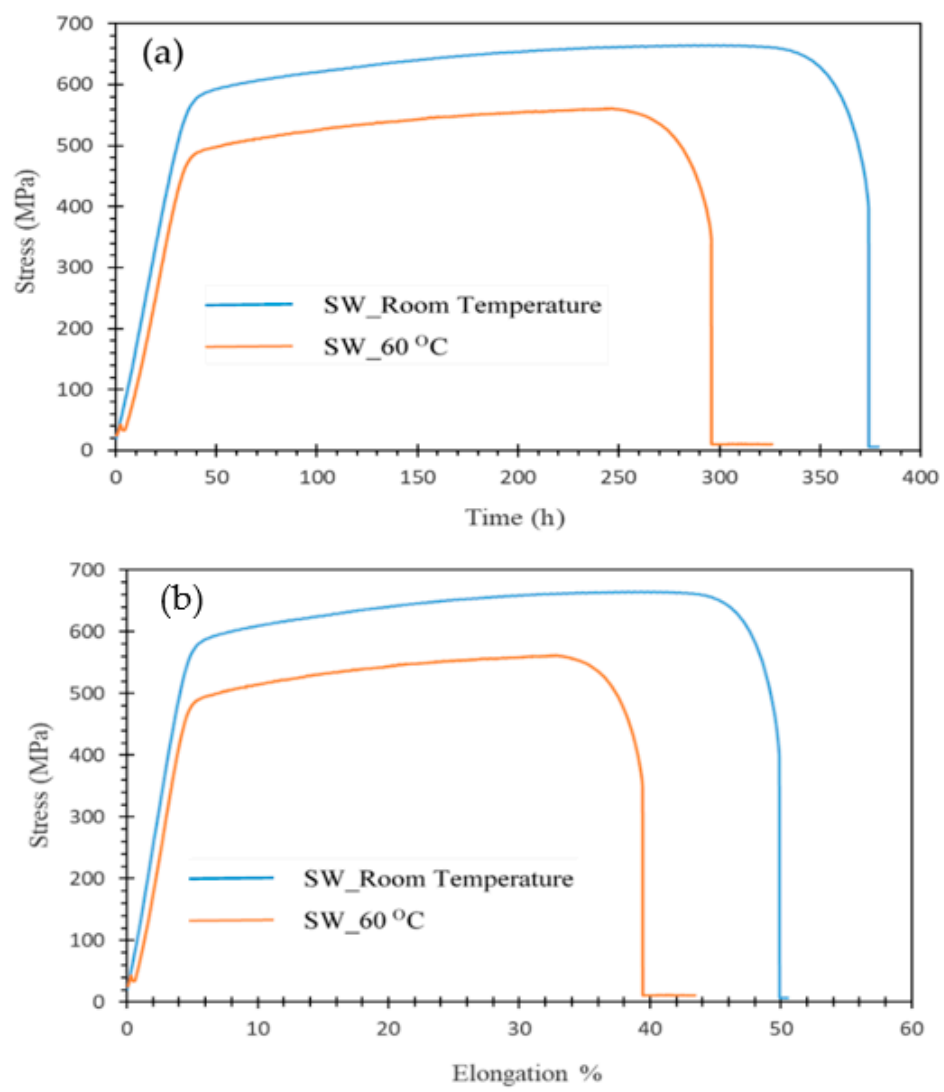

Figure 2. (a) Stress vs. time, and (b) stress vs. elongation plots of AISI 316 stainless steel alloy at strain rate of $3.7 \times 10^{-7} \mathrm{~s}^{-1}$ in the simulated SW solution at room temperature $\left(25^{\circ} \mathrm{C}\right)$ and $60{ }^{\circ} \mathrm{C}$.

It is necessary to ascertain whether SCC contributed to the shorter $t_{f}$, and lower $\varepsilon_{f}$ and UTS at $60{ }^{\circ} \mathrm{C}$, or these were simply just due the effect of higher temperature. Representative images of the fractographic features (Figure 3) suggest ductile dimples over almost the entire fracture surface of samples tested at $25^{\circ} \mathrm{C}$ (Figure 3a), confirming absence of SCC, 
whereas the fracture surface of samples tested at $60{ }^{\circ} \mathrm{C}$ has a few locations with features of SCC (Figure 3b).

(a)

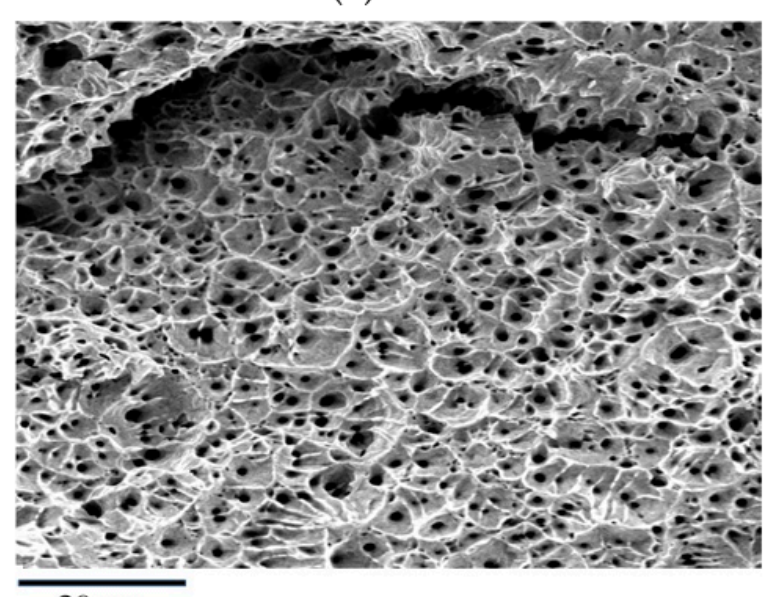

$20 \mu \mathrm{m}$ (b)

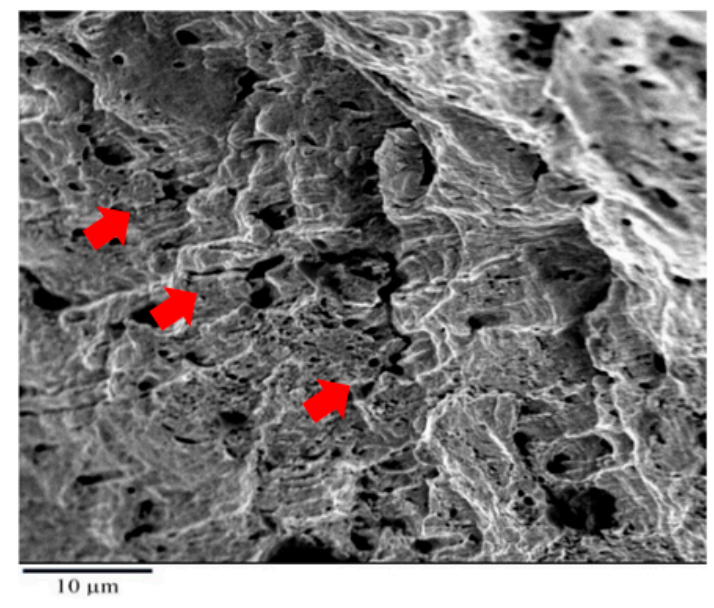

Figure 3. SEM fractography of 316 stainless steel samples tested in SW at: (a) $25^{\circ} \mathrm{C}$ and (b) $60{ }^{\circ} \mathrm{C}$. Arrows shows the features of SCC that were located in the areas adjacent to the sample edge.

Figure $4 \mathrm{a}, \mathrm{b}$ compare the stress vs. time and the stress vs. elongation plots respectively for AISI 316 stainless steel samples exposed to SW, NC and SWSSNC solutions at $60^{\circ} \mathrm{C}$. The $t_{f}, \varepsilon_{f}$ and UTS in NC and SWSSNC are greater than the corresponding data for SW, which may be attributed to the high alkalinity ( $\mathrm{pH}$ 13.4) of NC and SWSSC that facilitates the development of robust passive film [31,32], resulting in lesser corrosion-assisted loss of the sample cross-section. The corresponding similarities of the $t_{f}$ and $\varepsilon_{f}$ data for NC and SWSSC would suggest the passivating effect of high alkalinity in SWSSC (that is same as that in NC, i.e., $\mathrm{pH}$ 13.4) predominates the reported deleterious effect of high chloride content of SWSSC (35 g/l, i.e., same as seawater). As a result, both the environments seem to provide similar degrees of the lesser corrosion-assisted loss of the sample cross-section, and hence, corresponding similarities of the $t_{f}$ and $\varepsilon_{f}$. In contrast, SW that has no alkali content ( $\mathrm{pH} 7.5$ ) will have the well-known influence in disrupting the passive layer of stainless steel [33-35], accelerating corrosion and loss of cross-section of SSRT samples, and hence, much lower $t_{f}$ and $\varepsilon_{f}$ in SW (Figure $4 \mathrm{a}, \mathrm{b}$ ).

Again, SEM fractography was carried out to ascertain whether SCC contributed to the fracture of specimens in NC and SWSSNC at $60{ }^{\circ} \mathrm{C}$. Representative fractographic features (Figure 5) suggest only ductile dimples over the fracture surface, confirming absence of SCC in SWSSNC and NC at $60^{\circ} \mathrm{C}$.

One of the main degradation processes of the concrete structures is the alkali silica reaction (ASR) [36,37]. ASR occurs due to chemical reactions between hydroxyl ions in the pore water within the concrete matrix and certain forms of silica $[9,37,38]$. This reaction has a detrimental effect on ordinary Portland cement concrete which further deteriorates the integrity of the structure [9]. It causes cracking and collapse of concrete structures, including dams, bridges and pavements.

There is little reported on the effect of silicate in NC and SWSSC on SCC of steels. Figure $6 a, b$ present SSRT results of 316 stainless steel in the simulated solutions of NC and SWSSNC with silicate (i.e., NC_Sil and SWSSNC_Sil respectively, as described in Table 1). The presence of silicate in NC and SWSSNC causes considerable decreases in $t_{f}, \varepsilon_{f}$ and UTS in both NC_Sil and SWSSNC_Sil when compared to NC and SWSSNC (Table 2). For instance, the presence of silicate decreased the $t_{f}$ of 316 stainless steel samples by 19 and $47 \mathrm{~h}$ in the simulated solutions of NC_Sil and SWSSNC_Sil respectively (Figure 6a). Table 2 
shows scatters in $t_{f}, \varepsilon_{f}$ and UTS data of 316 stainless steel in the simulated solutions of NC, SWSSNC, NC_Sil and SWSSNC_Sil.
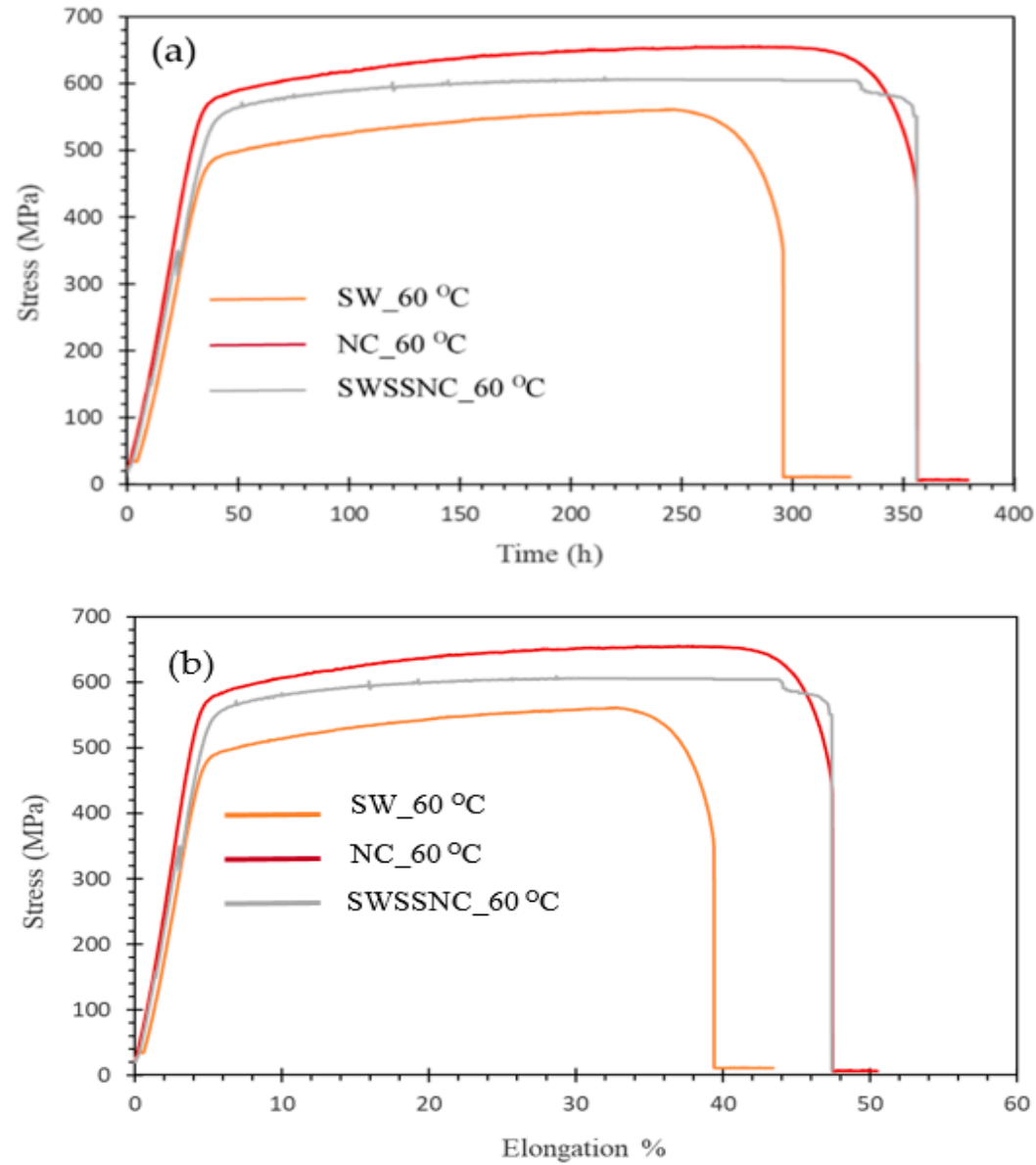

Figure 4. (a) Stress vs. time, and (b) stress vs. elongation plots of AISI 316 stainless steel alloy at strain rate of $3.7 \times 10^{-7} \mathrm{~s}^{-1}$ in the simulated solutions of SW, NC and SWSSNC at $60^{\circ} \mathrm{C}$.

(a)

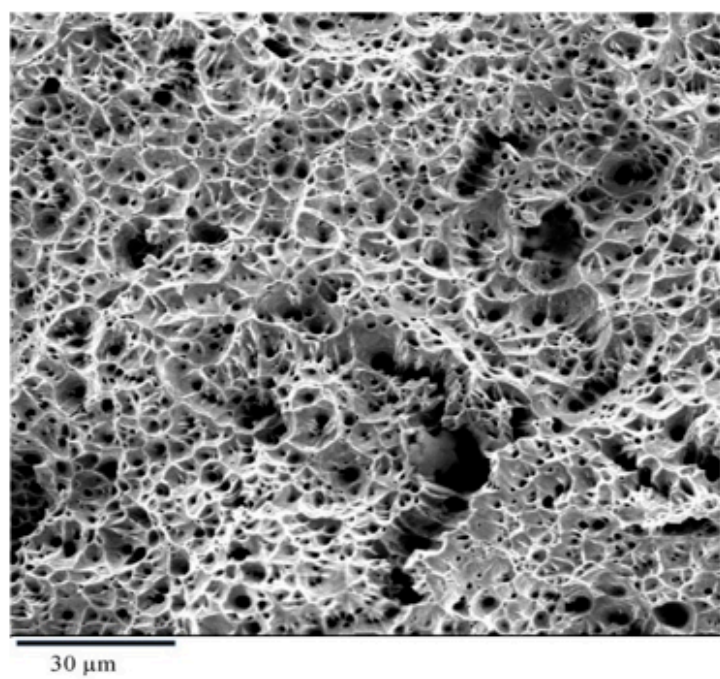

(b)

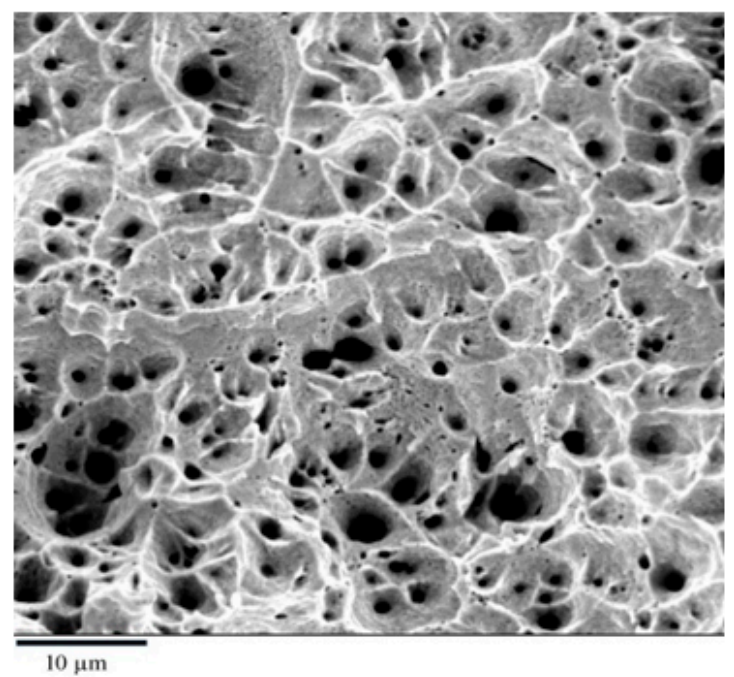

Figure 5. SEM fractography of 316 stainless steel samples tested in (a) NC and (b) SWSSNC at $60{ }^{\circ} \mathrm{C}$. 

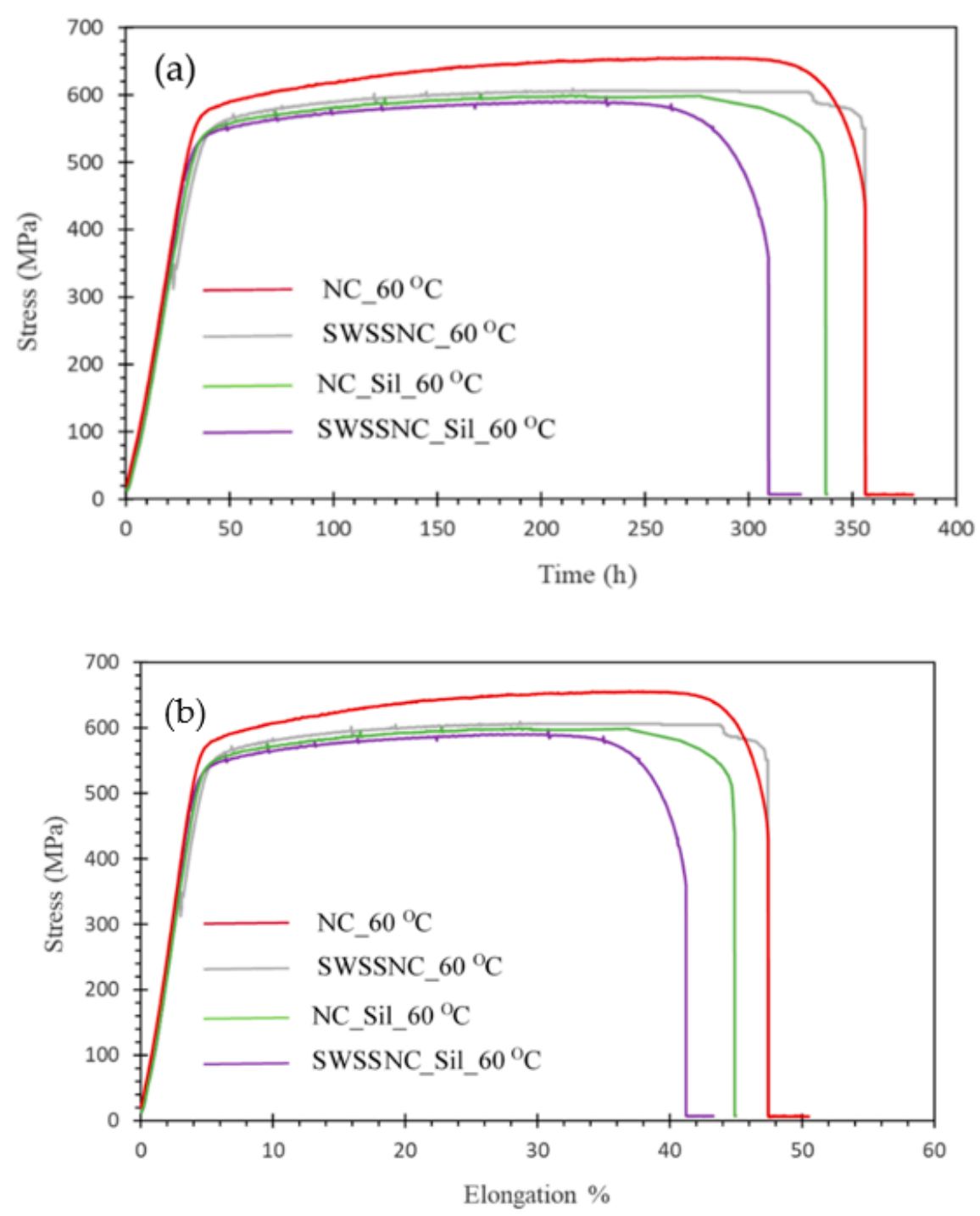

Figure 6. (a) Stress vs. time, and (b) stress vs. elongation plots of AISI 316 stainless steel alloy at strain rate of $3.7 \times 10^{-7} \mathrm{~s}^{-1}$ in the simulated solutions of NC and SWSSNC without and with silicate at $60^{\circ} \mathrm{C}$.

Table 2. The time to failure $\left(t_{f}\right)$, elongation to failure $\left(\varepsilon_{f}\right)$ and ultimate tensile strength (UTS) of 316 stainless steel samples in the simulated solutions of normal concrete (NC), seawater sea sand concrete (SWSSNC), NC with silica (NC_Sil) and SWSSC with silica (SWSSNC_Sil) at $60^{\circ} \mathrm{C}$.

\begin{tabular}{cccc}
\hline Simulated Solution & Time to Failure $\left(\boldsymbol{t}_{\boldsymbol{f}}, \mathbf{h}\right)$ & $\begin{array}{c}\text { Elongation to Failure } \\
\left(\varepsilon_{\boldsymbol{f}}, \boldsymbol{\%}\right)\end{array}$ & $\begin{array}{c}\text { Ultimate Tensile } \\
\text { Strength }(\text { UTS, MPa) }\end{array}$ \\
\hline NC & $356 \pm 6.8$ & $47.4 \pm 2.0$ & $652 \pm 6.6$ \\
SWSSNC & $356 \pm 2.4$ & $47.4 \pm 0.3$ & $606 \pm 1.9$ \\
NC_Sil & $337 \pm 5.2$ & $44.9 \pm 1.1$ & $598 \pm 3.9$ \\
SWSSNC_Sil & $309 \pm 6.5$ & $41.2 \pm 1.8$ & $596 \pm 6.0$ \\
\hline
\end{tabular}

Tang et al. [39] studied the corrosion behavior of steel in simulated concrete pore solutions in the presence of calcium silicate hydrate $(\mathrm{C}-\mathrm{S}-\mathrm{H})$. They found that the addition of silicate to the simulated concrete solution $(\mathrm{pH} 12.5)$ decreased passivation characteristics and increased the pitting corrosion sensitivity. The porous nature of C-S-H with high specific surface area enable it to adsorb the chloride ions effectively [39]. The accumulation of calcium ions near the interface can effectively attract chlorides and make them tightly 
bonded in spite of the electrostatic repulsion from the oxygen of surface silicate chains. Thus, the accumulation of calcium ions near the surface can effectively attract chloride ions [40].

SEM fractogarphy was carried out to find whether the shorter $t_{f}$, and lower $\varepsilon_{f}$ and UTS at $60^{\circ} \mathrm{C}$ in NC_Sil and SWSSNC_Sil could be attributed to SCC. The representative fractograph of the failed samples (Figure 7) suggests transgranular SCC over a considerable fraction of the fracture surface, whereas the rest of the fracture surface had ductile dimples. This observation suggests the deleterious role of silicate content in causing SCC.

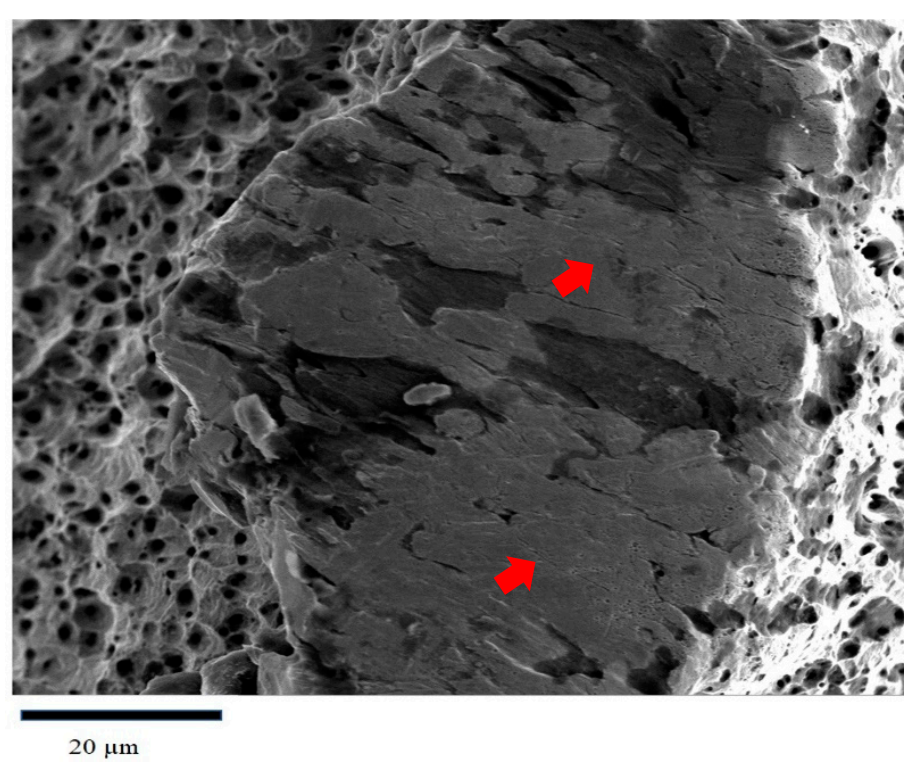

Figure 7. SEM fractography of 316 stainless steel samples tested in SWSSNC_Sil solutions at $60^{\circ} \mathrm{C}$. Arrows shows the features of SCC that were located in the areas adjacent to the sample edge.

Role of silica in deterioration of concrete due to alkali-silica reaction (ASR) is welldocumented. However, there is little reported on role of the silica content of concrete in stress corrosion cracking (SCC) of steel rebar. As demonstrated in Figure $6 \mathrm{a}, \mathrm{b}$ and Figure 7 , silica addition to simulated solutions of normal and seawater and sea sand concretes causes stress corrosion cracking to 316 stainless steel. This finding suggests additional advantage of silica-lean concretes (such as the geo-polymer concrete or the high-performance concrete that utilizes industrial waste materials such as fly ash or slag).

This study investigated the cylindrical samples of austenitic stainless steel. In actual practice, SS bars may be welded. It is well known that welding may introduce residual stresses as well as undesirable changes in the steel such as sensitization in heat affected zone, both of which can facilitate SCC [41]. These aspects are a matter of further study.

\section{Conclusions}

Use of seawater sea sand concrete (SWSSC) in place of normal concrete (NC) has great commercial and social implications. However, SWSSC may require stainless steel reinforcement (instead of mild steel used in NC). Stress corrosion cracking (SCC) of AISI 316 stainless steel (SS) was investigated at 25 and $60^{\circ} \mathrm{C}$ by slow strain rate testing (SSRT) at $3.7 \times 10^{-7} \mathrm{~s}^{-1}$, in simulated SWSSC and NC environments, with and without addition of silica (i.e., a constituent of concrete). SCC of SS was also investigated in simulated seawater (SW), for comparison. Following conclusions were drawn:

(a) SS showed no SCC at $25^{\circ} \mathrm{C}$ in any of the test solutions;

(b) At $60^{\circ} \mathrm{C}$, some indications of SCC were seen in SW, but no SCC in SWSSC or NC; 
(c) Highly passivating alkaline condition accounts for the absence of SCC in SWSSC and $\mathrm{NC}$ at $60^{\circ} \mathrm{C}$. The absence of SCC in SWSSC also suggests ineffectiveness of chloride content of SWSSC in causing SCC;

(d) The addition of silicate to SWSSC or NC caused transgranular SCC to SS at $60^{\circ} \mathrm{C}$, which may be the first finding of the role of silica in causing SCC to SS in concrete environment.

Author Contributions: R.K.S.R., conceptualization and planning of the work, supervision, funding and writing the manuscript; X.Y., conceptualization and planning of the work, experimental work, data analyses and writing the manuscript; S.A.-S., conceptualization and planning of the work, experimental work, data analyses, supervision and writing the manuscript; I.K., experimental work and data analyses; X.-L.Z., supervision, funding for the work and general technical discussions. All authors have read and agreed to the published version of the manuscript.

Funding: This research was funded by Australian Research Council (ARC) through an ARC Discovery Project Grant (DP160100739).

Institutional Review Board Statement: Not applicable.

Informed Consent Statement: Not applicable.

Data Availability Statement: Data is contained within the article.

Acknowledgments: The authors wish to acknowledge the financial support provided by the Australian Research Council (ARC) through an ARC Discovery Project Grant (DP160100739).

Conflicts of Interest: The authors declare no conflict of interest.

\section{References}

1. Teng, J.G. Performance enhancement of structures through the use of fiber reinforced polymer (FRP) composites. In Proceedings of the 23rd Australasian Conference on the Mechanics of Structures and Materials (ACMSM23), Lismore, NSW, Australia, 9 December 2014.

2. Qi, X.; Huang, Y.; Li, X.; Hu, Z.; Ying, J.; Li, D. Mechanical Properties of Sea Water Sea Sand Coral Concrete Modified with Different Cement and Fiber Types. J. Renew. Mater. 2020, 8, 915-937. [CrossRef]

3. Li, Y.; Zhao, X.; Singh, R.R.; Al-Saadi, S. Experimental study on seawater and sea sand concrete filled GFRP and stainless steel tubular stub columns. Thin Walled Struct. 2016, 106, 390-406. [CrossRef]

4. Xiao, J.; Qiang, C.; Nanni, A.; Zhang, K. Use of sea-sand and seawater in concrete construction: Current status and future opportunities. Constr. Build. Mater. 2017, 155, 1101-1111. [CrossRef]

5. Mohammed, T.U.; Hamada, H.; Yamaji, T. Performance of seawater-mixed concrete in the tidal environment. Cem. Concr. Res. 2004, 34, 593-601. [CrossRef]

6. Nishida, T.; Otsuki, N.; Ohara, H.; Garba-Say, Z.M.; Nagata, T. Some Considerations for Applicability of Seawater as Mixing Water in Concrete. J. Mater. Civ. Eng. 2015, 27, 4014004. [CrossRef]

7. Zhang, G.L.; Chen, J.B.; Mo, L.W.; Liu, J.Z.; He, Z.M. Research on Influence of Fly Ash on the Microstructural Characteristics of Sea Sand Concrete. Appl. Mech. Mater. 2012, 204, 3831-3834. [CrossRef]

8. Japan Concrete Institute Technical Committee. Report on the Use of Seawater in Concrete Japan; Japan Concrete Institute: Tokyo, Japan, 2015.

9. Swamy, R.N.; All-Asali, M.M. Effect of Alkali-Silica Reaction on the Structural Behavior of Reinforced Concrete Beams. ACI Struct. J. 1989, 86, 451-459.

10. Multon, S.; Sellier, A. Multi-scale analysis of alkali-silica reaction (ASR): Impact of alkali leaching on scale effects affecting expansion tests. Cem. Concr. Res. 2016, 81, 122-133. [CrossRef]

11. Verbruggen, H.; Terryn, H.; De Graeve, I. Inhibitor evaluation in different simulated concrete pore solution for the protection of steel rebars. Constr. Build. Mater. 2016, 124, 887-896. [CrossRef]

12. Li, C.Q.; Zheng, J.J.; Lawanwisut, W.; Melchers, R.E. Concrete Delamination Caused by Steel Reinforcement Corrosion. J. Mater Civ. Eng. 2007, 19, 591-600. [CrossRef]

13. Vacek, V.; Kolisko, J.; Pokorný, P.; Kostelecká, M. Steel Reinforcement Corrosion-Its Impact on Features of Steel PSC Strand. Key Eng. Mater. 2020, 868, 57-64. [CrossRef]

14. Alhozaimy, A.; Hussain, R.R.; Al-Zaid, R.; Al Negheimish, A. Investigation of severe corrosion observed at intersection points of steel rebar mesh in reinforced concrete construction. Constr. Build. Mater. 2012, 37, 67-81. [CrossRef]

15. Cramer, S.; Covino, B.; Bullard, S.; Holcomb, G.; Russell, J.; Nelson, F.; Laylor, H.; Soltesz, S. Corrosion prevention and remediation strategies for reinforced concrete coastal bridges. Cem. Concr. Compos. 2002, 24, 101-117. [CrossRef] 
16. Jones, D. The Technology and Evaluation of Corrosion, Principles and Prevention of Corrosion, 2nd ed.; Prentice-Hall: Upper Saddle River, NJ, USA, 1996; pp. 3-4.

17. Xie, Y.; Zhang, J.; Aldemir, T.; Denning, R. Multi-state Markov modeling of pitting corrosion in stainless steel exposed to chloride-containing environment. Reliab. Eng. Syst. Saf. 2018, 172, 239-248. [CrossRef]

18. Fontana, M.G. Corrosion Engineering; Tata McGraw-Hill Education: New York, NY, USA, 2005.

19. Briz, E.; Biezma, M.; Bastidas, D. Stress corrosion cracking of new 2001 lean-duplex stainless steel reinforcements in chloride contained concrete pore solution: An electrochemical study. Constr. Build. Mater. 2018, 192, 1-8. [CrossRef]

20. Li, Y.; Zhao, X.; Raman, R.S.; Yu, X. Axial compression tests on seawater and sea sand concrete-filled double-skin stainless steel circular tubes. Eng. Struct. 2018, 176, 426-438. [CrossRef]

21. Raman, R.S.; Siew, W. Role of nitrite addition in chloride stress corrosion cracking of a super duplex stainless steel. Corros. Sci. 2010, 52, 113-117. [CrossRef]

22. Parrott, R.; Pitts, H.; Hill, H.D. Chloride Stress Corrosion Cracking in Austenitic Stainless Steel; The Health and Safety Laboratory for the Health and Safety Executive: Buxton, UK, 2011.

23. Vu, N.A.; Castel, A.; François, R. Effect of stress corrosion cracking on stress-strain response of steel wires used in prestressed concrete beams. Corros. Sci. 2009, 51, 1453-1459. [CrossRef]

24. Raman, R.K.S. Evaluation of caustic embrittlement susceptibility of steels by slow strain rate testing. Met. Mater. Trans. 2005, 36, 1817-1823. [CrossRef]

25. Truman, J. The influence of chloride content, $\mathrm{pH}$ and temperature of test solution on the occurrence of stress corrosion cracking with austenitic stainless steel. Corros. Sci. 1977, 17, 737-746. [CrossRef]

26. Chen, Y.; Davalos, J.F.; Ray, I.; Kim, H.-Y. Accelerated aging tests for evaluations of durability performance of FRP reinforcing bars for concrete structures. Compos. Struct. 2007, 78, 101-111. [CrossRef]

27. Guo, F.; Khoo, W.; Al-Saadi, S.H.M.; Li, Y.; Singh, R.R.K.; Zhao, X.L. Preliminary study on durability of FRP and stainless steel in seawater and sea sand concrete (SWSSC) environment. In Proceedings of the ASCCS International Conference on Steel-Concrete Composite and Hybrid Structures 2015, Beijing, China, 3-5 December 2015; pp. 1-8.

28. Guo, F.; Al-Saadi, S.; Raman, R.S.; Zhao, X. Durability of fiber reinforced polymer (FRP) in simulated seawater sea sand concrete (SWSSC) environment. Corros. Sci. 2018, 141, 1-13. [CrossRef]

29. Wang, Z.; Zhao, X.-L.; Xian, G.; Wu, G.; Raman, R.S.; Al-Saadi, S.; Haque, A. Long-term durability of basalt- and glass-fibre reinforced polymer (BFRP/GFRP) bars in seawater and sea sand concrete environment. Constr. Build. Mater. 2017, 139, 467-489. [CrossRef]

30. Wang, Z.; Zhao, X.; Xian, G.; Wu, G.; Raman, R.S.; Al-Saadi, S. Tensile properties of basalt-fibre reinforced polymer (BFRP) bars within seawater and sea sand concrete environment. In Proceedings of the 7th International Conference on Fibre-Reinforced Polymer (FRP) Composites in Civil Engineering (CICE 2016), Hong Kong, China, 14-16 December 2016.

31. Zhang, B.; Hao, S.; Wu, J.; Li, X.; Li, C.; Di, X.; Huang, Y. Direct evidence of passive film growth on 316 stainless steel in alkaline solution. Mater. Charact. 2017, 131, 168-174. [CrossRef]

32. Beverskog, B.; Puigdomenech, I. Pourbaix Diagrams for the Ternary System of Iron-Chromium-Nickel. Corrosion 1999, 55, 1077-1087. [CrossRef]

33. Saremi, M.; Mahallati, E. A study on chloride-induced depassivation of mild steel in simulated concrete pore solution. Cem. Concr. Res. 2002, 32, 1915-1921. [CrossRef]

34. Leek, D.S.; Poole, A.B. The Breakdown of the Passive Film on High Yield Mild Steel by Chloride Ions. Corrosion of Reinforcement in Concrete. In Proceedings of the Third International Symposium on Corrosion of Reinforcement in Concrete Construction, Wishaw, Warwickshire, UK, 21-24 May 1990.

35. Elfström, B.-O. The effect of chloride ions on passive layers on stainless steels. Mater. Sci. Eng. 1980, 42, 173-180. [CrossRef]

36. Figueira, R.; Sousa, R.; Coelho, L.; Azenha, M.; De Almeida, J.; Jorge, P.; Silva, C. Alkali-silica reaction in concrete: Mechanisms, mitigation and test methods. Constr. Build. Mater. 2019, 222, 903-931. [CrossRef]

37. Santos, M.B.; De Brito, J.; Silva, A.S. A Review on Alkali-Silica Reaction Evolution in Recycled Aggregate Concrete. Materials 2020, 13, 2625. [CrossRef]

38. Diamond, S. A review of alkali-silica reaction and expansion mechanisms Alkalies in cements and in concrete pore solutions. Cem. Concr. Res. 1975, 5, 329-345. [CrossRef]

39. Tang, Y.; Miao, Y.; Zuo, Y.; Zhang, G.; Wang, C. Corrosion behavior of steel in simulated concrete pore solutions treated with calcium silicate hydrates. Constr. Build. Mater. 2012, 30, 252-256. [CrossRef]

40. Zhou, Y.; Hou, D.; Jiang, J.; Liu, L.; She, W.; Yu, J. Experimental and molecular dynamics studies on the transport and ab-sorption of chloride ions in the nano-pores of calcium silicate phase: The influence of calcium to silicate ratios. Microporous Mesoporous Mater. 2018, 255, 23-35. [CrossRef]

41. Świerczyńska, A.; Fydrych, D.; Landowski, M.; Rogalski, G.; Łabanowski, J. Hydrogen embrittlement of X2CrNiMoCuN25-6-3 super duplex stainless steel welded joints under cathodic protection. Constr. Build. Mater. 2020, 238, 117697. [CrossRef] 